\title{
Ecotourism and Environmental Sustainability: Principles and Practice
}

J. Hill and T. Gale. (eds). Ashgate Publishing Limited, Farnham, England, 2009. 259 pp. + xv. Price £55 (hardback). ISBN 9780754672623.

A collection of contributions from a 2006 meeting in the UK, this compilation is rather a mixed bag. Most of its material has already been published elsewhere. Of course, the editors of this volume did not have the opportunity to specify topics or select authors, since it is essentially a conference proceedings. No criticism, therefore, for their editorial efforts. This volume does not really have either enough solid new content, however, or a sufficiently strong theme or structure, to substitute for the primary literature.

There are five very general chapters, and nine case studies. The latter look at: the Andes and Himalayas; a heavily-visited Biosphere Reserve in China; cruise ships in the Canadian Arctic; bears in Alaska; tigers in India; dingoes in Australia; seals in New Zealand; tropical forests; and botanical gardens. From an ecologist's perspective, however, the data are rather disappointing, and the depth and detail of the case study chapters differs enormously.

The chapter by Alton Byers of The Mountain Institute, for example, successfully condenses decades of field experience into a succinct and reliable digest of issues and information associated with management of tourism and environment at Mt Everest and Mt Huascaran. It gets to the point and leaves the reader with a good sense of real-world practice.

Li Wenjun's chapter on Jiuzhaigou in China is also very interesting and rich in data, but a little lacking in context. It says little of the pre-park history of large-scale logging - yet recovery of vegetation is surely due more to a halt in logging than to commercial arrangements between park managers and guesthouse owners, admirable though these may be. I have not visited Jiuzhaigou myself, but a 2009 article in National Geographic, as well as travellers' blogs, paint a rather less rosy picture. Li's data are based largely on interviews, but surely the fact that these were conducted in Chinese even though the local residents are largely of Tibetan ethnic extraction (p. 75) would colour the interviewees' responses? Income in villages on the main access road has shifted from agriculture to tourism (pp. 78-79) but total income (p. 76) has in fact only grown at around 4\% per annum, surely attributable solely to inflation. Li's chapter says that the village of Zaru has been involved only indirectly in 
tourism; but current information on Jiuzhaigou (Zhong et al., 2010) mentions a new tourist route at Zaru, so perhaps Li’s 2006 article was not updated for this 2009 book.

Some of the other chapters, whilst incorporating interesting snippets, seem to be based on limited data and rather severely lacking in academic rigour, and leave one uncertain as to how relevant or reliable their authors' conclusions may be. The chapter by Simpson rightly draws attention to the irony in New Zealand's “ $100 \%$ pure” marketing campaign, given the extensive clearance of native vegetation, extinctions of native wildlife, and invasions by weeds and feral animals. His chapter then, however, completely misquotes an article on narwhal tourism and local hunting in the Canadian article, making completely erroneous statements which do not appear in that article at all. (I can speak confidently since, as it happens, I wrote it.) For example, Simpson says that ecotourists hampered Inuit hunters, travelled in a motor launch, and bought narwhal tusks, none of which are correct.

The management of tourism to reduce its negative impacts on the natural (and social) environment and, where possible, to generate positive gains for conservation is indeed an important topic for ecologists, and one now quite well studied and reviewed. Hill and Gale certainly picked an important topic for their 2006 meeting, and some of the resulting chapters will indeed stand the test of time. I would not, however, go as far as the back-cover blurb urging researchers to keep this volume "on their desk". In the bookcase will be fine.

\section{Reference}

Zhong, L-S., Qi, J-H. and Buckley, R.C. (2010) China. In: Buckley, R.C., Conservation Tourism. CAB International, Wallingford (in press).

Ralf Buckley, Director International Centre for Ecotourism Research, Griffith University, Australia. Phone: 075552 8675, Fax: 075552 8895, E mail r.buckley@griffith.edu.au 